\title{
Cyclopentadienone Iron Tricarbonyl Complexes-Catalyzed Hydrogen Transfer in Water
}

\author{
Daouda Ndiaye ${ }^{1,2}$, Sébastien Coufourier ${ }^{1}\left(\mathbb{D},{\text { Mbaye Diagne } \text { Mbaye }^{2} \text {, Sylvain Gaillard }}^{1}\right.$ and \\ Jean-Luc Renaud $1, * \mathbb{B}$
}

1 Normandie Univ., LCMT, ENSICAEN, UNICAEN, CNRS, 6 boulevard du Maréchal Juin, 14050 Caen, France; daouda.ndiaye79@gmail.com (D.N.); coufourier.sebastien@gmail.com (S.C.); sylvain.gaillard@ensicaen.fr (S.G.)

2 Université Assane Seck de Ziguinchor, BP 523, Ziguinchor, Senegal; mmbaye@univ-zig.sn

* Correspondence: jean-luc.renaud@ensicaen.fr; Tel.: +33-231-452842

Academic Editor: Hans-Joachim Knölker

Received: 30 December 2019; Accepted: 17 January 2020; Published: 20 January 2020

\begin{abstract}
The development of efficient and low-cost catalytic systems is important for the replacement of robust noble metal complexes. The synthesis and application of a stable, phosphine-free, water-soluble cyclopentadienone iron tricarbonyl complex in the reduction of polarized double bonds in pure water is reported. In the presence of cationic bifunctional iron complexes, a variety of alcohols and amines were prepared in good yields under mild reaction conditions.
\end{abstract}

Keywords: iron complexes; hydrogen transfer; reductive amination; alcohols; amines

\section{Introduction}

The reduction of polarized $\mathrm{C}=\mathrm{X}$ bonds is an important process, both in industry and in academia, for the synthesis of fine chemicals, perfumes, agrochemicals, and pharmaceuticals [1-8]. To avoid the use of stoichiometric amounts of borohydrides or aluminium hydrides, metal-catalyzed pathways to amines and alcohols have been introduced [9-14]. These procedures consist of hydrogenation, hydrosilylation, and transfer hydrogenation (with iso-propanol or formic acid) and involve mainly platinum complexes $[9,10]$, but recent contributions highlighted the rise of Earth-abundant metals for such reductions [11-14]. Hydrogenation is the most atom economical approach, but requires hydrogen gas handling and consequently implies some safety issues. Hydrogen transfer (TH) is an alternative pathway and a more practical tool. Alcohols and formic acid (or formates) are among the most advantageous hydride donors.

Water is a non-toxic, non-flammable, non-explosive and also an economically relevant solvent $[15,16]$. Water-soluble organometallic complexes have attracted some interest because of the environmentally acceptable process, the simple product separation and, in some reactions, the possibility to control the selectivity by adjusting the $\mathrm{pH}[15,16]$. Despite these advantages, the use of water in catalysis, and more specifically, in reduction, still constitutes a challenge and is underexplored compared to organic solvent $[17,18]$. Hydrogenation of ketones and imines [19], and reductive amination [20] in water have been reported with few iron complexes. As an example; our group has disclosed the first water-soluble and well-defined cyclopentadienone iron complex able to catalyze the reduction of aldehydes, ketones, and 2-substituted dihydroisoquinolines in pure water at $85-100{ }^{\circ} \mathrm{C}$ under hydrogen pressure (Figure 1, for the first synthesis of a water-soluble cyclopentadienone iron complex, see [19]). Little is known on the transfer hydrogenation with Earth-abundant complexes, while formates are used by enzymes for enantioselective reduction. To the best of our knowledge, excepted the hydrogen transfer reduction of heterocyclic compounds with formic acid catalyzed by a cobalt-phosphines complex [20], no reduction of polarized $C=X$ bonds (aldehydes, ketones, and 
imines) with formic acid derivatives has been yet reported. Toward this objective, we thought of developing new water-soluble non-phosphine ligand iron complexes for the reduction of polarized bonds in the presence of formates or formic acid in pure water.

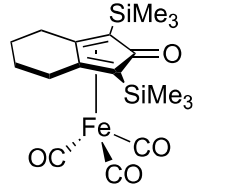

Fe1

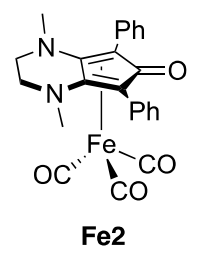

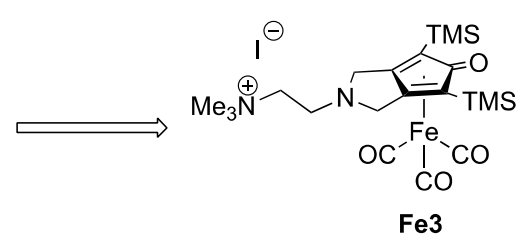

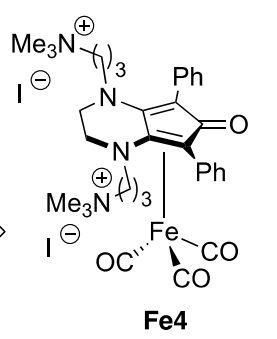

Renaud 2013: hydrogenation in pure water

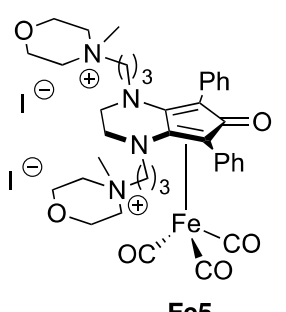

This work: transfer hydrogenation

Figure 1. Previous water-soluble cyclopentadienone iron complex and new complexes for application reduction.

In 2015, we introduced in catalysis the tricarbonyl iron complex Fe2 bearing a diaminocyclopentadienone ligand [21]. Compared to other cyclopentadienone iron carbonyl complexes, this phosphine-free iron complex has, to the best of our knowledge, the highest catalytic activities to date in reductive amination [21], in chemoselective reduction of $\alpha, \beta$-unsaturated ketones [22], in the hydrogenation of carbon dioxide [23], in alkylation of ketones [24-27], amines [25,28], oxindoles [29], indoles [25,30] and alcohols [31,32]. In our ongoing interest in reduction and alkylation, we thought that a water-soluble analog of Fe2 would be more active than our previous water-soluble cyclopentadienone iron complex Fe3 (Figure 1). In this work, we report on the synthesis and application of two water-soluble cyclopentadienone iron complexes in the reduction of aldehydes and in reductive amination in pure water.

\section{Results and Discussion}

\subsection{Synthesis of Complexes}

To develop water-soluble iron complexes, we selected a diaminocyclopentadienone ligand bearing ammonium functionalities [33]. The tetraamines 2 and $\mathbf{4}$ were prepared from diethyloxalate and $\mathrm{N}, \mathrm{N}$-dimethylpropylenediamine and $\mathrm{N}$-aminopropylenemorpholine via an amidation followed by a reduction in good overall yield (93 and 95\%, respectively). The corresponding aminocyclopentadienone ligands 1 and 2 were then prepared by reacting the amines 2 and $\mathbf{4}$ with the cyclopentatrienone in refluxing methanol for $16 \mathrm{~h}$ and were isolated in moderate yield (62\% and $88 \%$, respectively, Scheme 1$)$. The complexes Fe6 and Fe7 were synthesized in $48 \%$ and $76 \%$ yield by simple heating of the corresponding amino ligand with $\left[\mathrm{Fe}_{2}(\mathrm{CO})_{9}\right]$ in refluxing toluene (Scheme 1). Finally, the water-soluble bifunctional iron complexes $\mathrm{Fe} 4$ and Fe5 bearing ionic frameworks were obtained in almost quantitative yields after a subsequent alkylation of the pendant amines with iodomethane (Scheme 1) [33]. These complexes were fully characterized by ${ }^{1} \mathrm{H}-,{ }^{13} \mathrm{C}-\mathrm{NMR}$, and IR spectroscopies (see Supplementary Materials). These analyses showed that complexes Fe2 and Fe4-Fe7 have similar features. The back donation from the metal center to the CO ligands is more significant than in the Knölker's complex Fe1 [34,35]. Thus, the CO stretching frequencies were at 2032, 1961, and $1919 \mathrm{~cm}^{-1}$ and at 2015 and $1967 \mathrm{~cm}^{-1}$ in the neutral complexes Fe6 and Fe7, respectively, at 2038 and $1955 \mathrm{~cm}^{-1}$ and at 2034 and $1957 \mathrm{~cm}^{-1}$ in the ionic complexes Fe4 and Fe5, respectively. These frequencies are comparable to those 
of the analog Fe2 (2027, 1962 and $\left.1947 \mathrm{~cm}^{-1}\right)$ and lower than those of the Knölker's complex Fe1 (2061, 2053, and $\left.1987 \mathrm{~cm}^{-1}\right)$ or its water-soluble analog Fe3 (2066, 2016, and $\left.1996 \mathrm{~cm}^{-1}\right)$ [19].
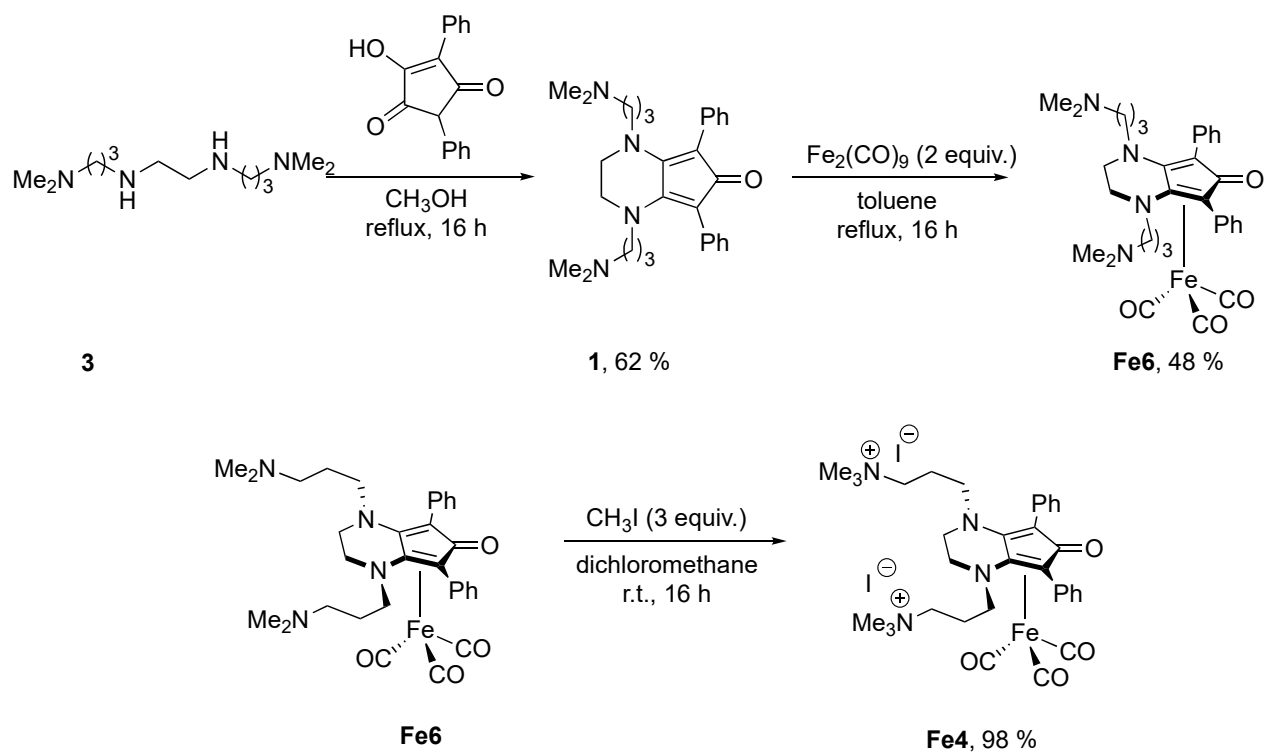

Fe4, $98 \%$

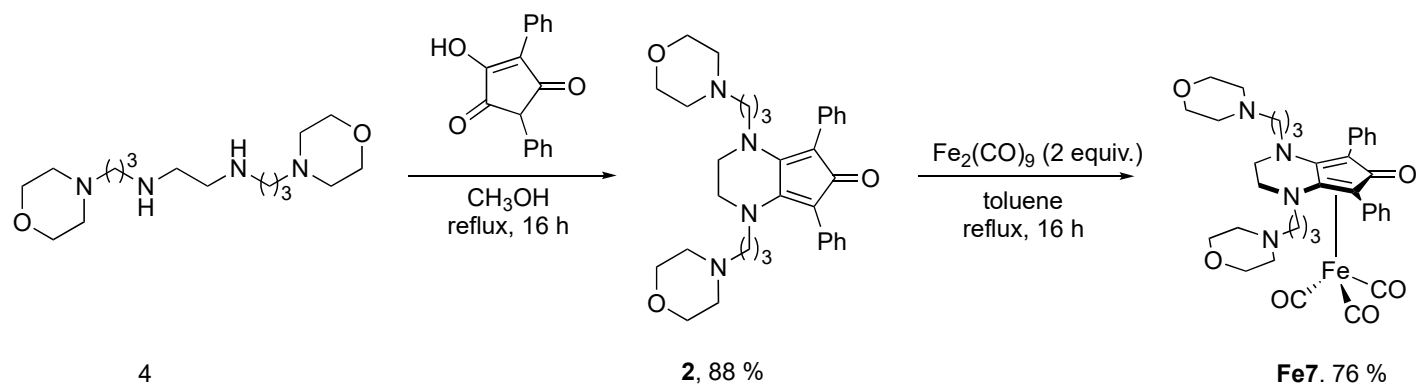

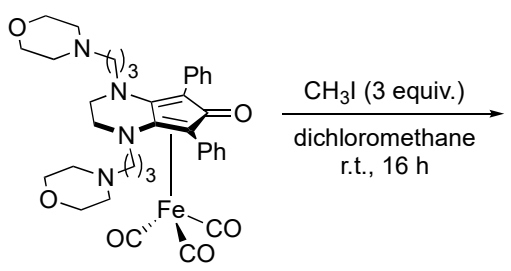

$\mathrm{Fe} 7$

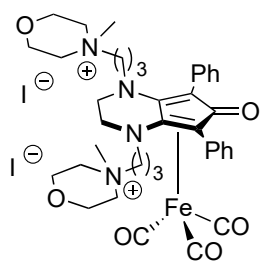

Fe5. quant.

Scheme 1. Synthesis of the iron complexes Fe4, Fe5, Fe6, and Fe7.

\subsection{Iron-Catalyzed Reduction of Carbonyl Compounds}

With these complexes in hands, we evaluated their catalytic activities in the reduction of 4-methoxybenzaldehyde as a benchmark reaction. Various methods of activation can be used with the cyclopentadienone iron carbonyl complexes [34-44]. We applied in this work the activation with $\mathrm{Me}_{3} \mathrm{NO}$ as oxidant [34-42]. Our first attempt with formic acid, in the presence of $2 \mathrm{~mol} \%$ of Fe4 and $2.5 \mathrm{~mol} \%$ of $\mathrm{Me}_{3} \mathrm{NO}$ at $100{ }^{\circ} \mathrm{C}$ for $24 \mathrm{~h}$ in $2 \mathrm{~mL}$ of pure water (concentration of $0.5 \mathrm{M}$ ), was unsuccessful as no reduction was noticed (entry 1, Table 1). In sharp contrast, in the same reaction conditions, complete conversions were obtained with different formate salts (entries 2-5, Table 1). Without a hydride donor or iron complex, no reduction occurred (entries 6-7, Table 1). Decreasing the reaction time (entries 8 and 11, Table 1), the catalyst loading (entry 13) and the amount of formate (entry 14) led to a drop in the conversion. No variation of the conversion was noticed by lowering the temperature to $80^{\circ} \mathrm{C}$ (entries 3 and 9, Table 1), while, at $60^{\circ} \mathrm{C}$, the conversion was only $75 \%$ (entry 
12). To our surprise, the first generation water-soluble cyclopentadienone iron complex Fe3 did not catalyze the reduction of 4-methoxybenzaldehyde in these conditions, while Fe5 appeared as active as Fe4 (entries 10-15, Table 1). Finally, the best conditions for the reduction of 4-methoxybenzaldehyde into the corresponding alcohol 4a were: $1 \mathrm{mmol}$ of aldehyde, in the presence of five equivalents of sodium formate in $2 \mathrm{~mL}$ of water, $2 \mathrm{~mol} \%$ of Fe4 or Fe5 and $2.5 \mathrm{~mol} \%$ of $\mathrm{Me}_{3} \mathrm{NO}$ at $80{ }^{\circ} \mathrm{C}$ for $24 \mathrm{~h}$.

Table 1. Optimization of the reaction conditions for the aldehyde reduction ${ }^{\text {a }}$.

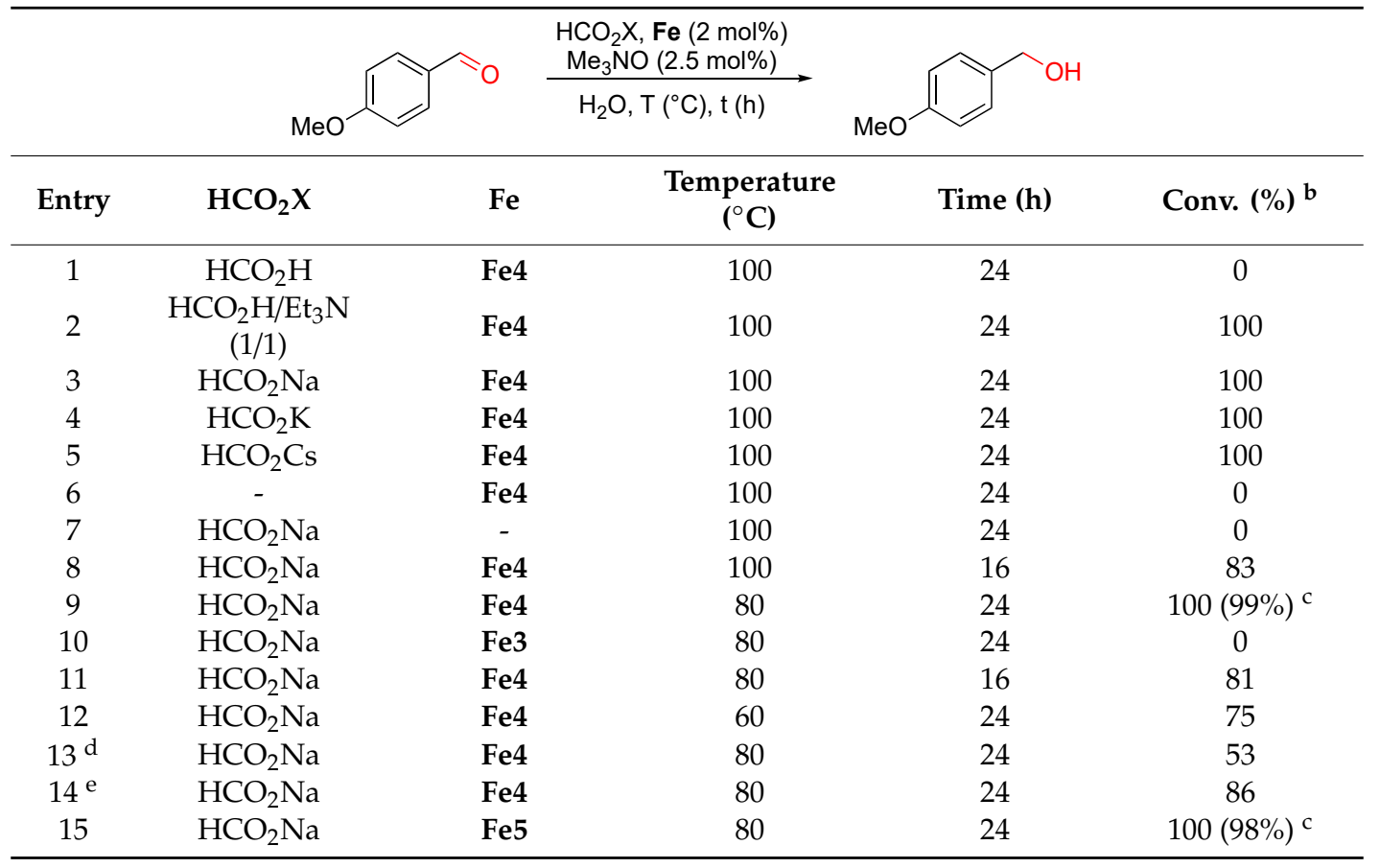

a General conditions: $\mathrm{HCO}_{2} \mathrm{X}$ ( $5 \mathrm{mmol}, 5$ equiv.), 4-methoxybenzaldehyde $(1 \mathrm{mmol})$, pre-catalyst $(2 \mathrm{~mol} \%), \mathrm{Me}_{3} \mathrm{NO}$ $(2.5 \mathrm{~mol} \%)$, water $(2 \mathrm{~mL}) .{ }^{\mathrm{b}}$ Conversion was determined by ${ }^{1} \mathrm{H}-\mathrm{NMR}$ spectroscopy analysis. ${ }^{\mathrm{c}}$ Isolated yield in the bracket. ${ }^{\mathrm{d}} \mathbf{F e} 0(1 \mathrm{~mol} \%), \mathrm{Me}_{3} \mathrm{NO}(1.25 \mathrm{~mol} \%)$ were used. ${ }^{\mathrm{e}} \mathrm{HCO}_{2} \mathrm{Na}(3 \mathrm{mmol}$, three equiv.) were used.

Having established the optimized conditions, we delineated the scope of the carbonyl derivatives (Table 2). Both electron-donating (methoxy, methyl, acetal substituents) and electron-withdrawing (nitro, nitrile, and ester substituents) groups were tolerated in this reduction. The corresponding alcohols $\mathbf{4 a - \mathbf { m }}$ were isolated in excellent yields in all examples (91-99\%, Table 2). No reduction

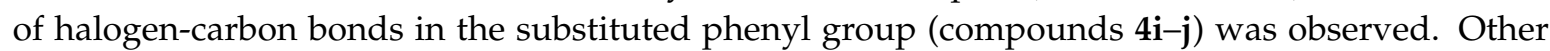
reducible functions, such as ester or nitrile, were preserved in these conditions. Heteroaromatic derivatives, such as pyridine or thiophene carboxaldehyde, furfural, did not impede the catalytic activity and provided the alcohols $4 \mathbf{n}-\mathbf{r}$ in $75-98 \%$ yield (Table 2). Finally, to extend the scope, aliphatic aldehydes were also engaged in this reduction and the corresponding alcohols $4 \mathbf{s}-\mathbf{v}$ were isolated in 92-99\% yield (Table 2). It is worth to mention that (i) ethanol was used as a co-solvent with some substrates to facilitate the solubility and consequently enhanced the reactivity; and (ii) no reaction occurred in a mixture of water and ethanol without sodium formate. 
Table 2. Iron-catalyzed reduction of aldehydes with sodium formate ${ }^{\mathrm{a}}$.

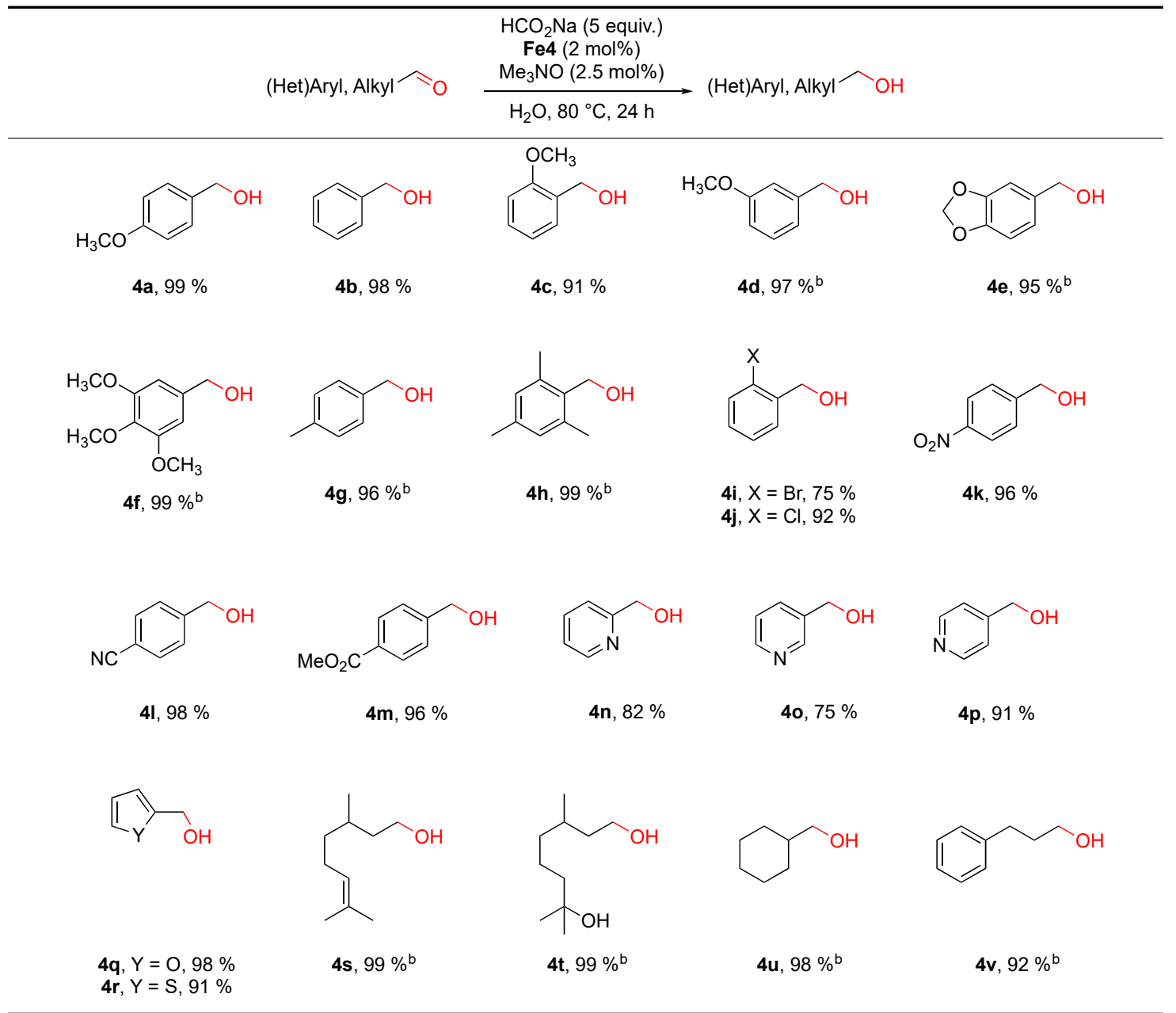

${ }^{\mathrm{a}}$ General conditions: aldehyde ( $\left.1 \mathrm{mmol}\right), \mathrm{HCO}_{2} \mathrm{Na}\left(5 \mathrm{mmol}, 5\right.$ equiv.), pre-catalyst Fe4 (2 mol \%), $\mathrm{Me}_{3} \mathrm{NO}(2.5 \mathrm{~mol}$ $\%)$, water $(2 \mathrm{~mL}) .{ }^{\mathrm{b}} \mathrm{H}_{2} \mathrm{O} / \mathrm{EtOH} 1 / 1$.

\subsection{Iron-Catalyzed Reductive Amination}

Having established a simple protocol for the reduction of aldehydes in water, we thought to extend this work to the synthesis of amines. Amines are usually prepared via the reduction of $\mathrm{C}=\mathrm{N}$ bonds either in catalytic conditions under hydrogen pressure or in stoichiometric conditions in the presence of aluminum/boron hydride [45]. However, imines are not always easily prepared and cannot be stable. Reductive amination of aldehydes constitutes a direct route to amines, without requiring any purification of the imine intermediate. Many efforts have been devoted to the development of reductive amination [46-48]. For example, in iron chemistry, Bhanage described that a combination of iron sulfate and ethylenediaminetetraacetic acid (EDTA) catalyzed a reductive amination under hydrogen pressure (400 psi) in water at elevated temperatures $\left(150^{\circ} \mathrm{C}\right)$ [20]. Beller reported a reductive amination with anilines catalyzed by $\mathrm{Fe}_{2}(\mathrm{CO})_{9}$ under high hydrogen pressure and elevate temperature [49]. We have reported that cyclopentadienone iron tricarbonyl complexes $[21,34,35]$ or cyclopentadienyl iron(II) tricarbonyl complex [50] were able to catalyzed the reductive alkylation of various amines and carbonyl derivatives under 5 bar of hydrogen, at $40-70{ }^{\circ} \mathrm{C}$ and even room temperature. To avoid the use of a large amount of hydride (and the concomitant formation of wastes) or the handling of gas, hydrogen transfer with formate derivatives appears as a simple and versatile procedure. The reductive alkylation of $\mathrm{N}$-methylbenzylamine with citronellal was chosen as a model reaction for the optimization of the reaction conditions. Three formate salts were tested, and the cation appeared to be crucial for the catalytic activity (entries 1-4, Table 3). Indeed, the ammonium favored both the condensation and the 
reduction (via the formation of an iminium intermediate). Fe4 and Fe5 provided the alkylated amines with the same conversion and selectivities (entries 1-2, Table 3). Both water-soluble complexes Fe4 and Fe 5 could then be used in this reaction (as it was also mentioned in the reduction of aldehydes), but for the rest of the study, we will use Fe 5 as pre-catalyst as the overall conversion in reductive amination is somewhat higher. Without a hydride donor, no reduction occurred (entries 5, Table 3), and only the imine was obtained. Decreasing the temperature was detrimental to the catalytic activity as a drop of the conversion in amine was noticed (entries 6-8, Table 3). Finally, an increase of the amount of ammonium formate to 6.5 equivalent furnished the alkylated amine in $70 \%$ isolated yield (entry 9 , Table 3).

Table 3. Optimization of the reaction conditions for the reductive amination ${ }^{\mathrm{a}}$.

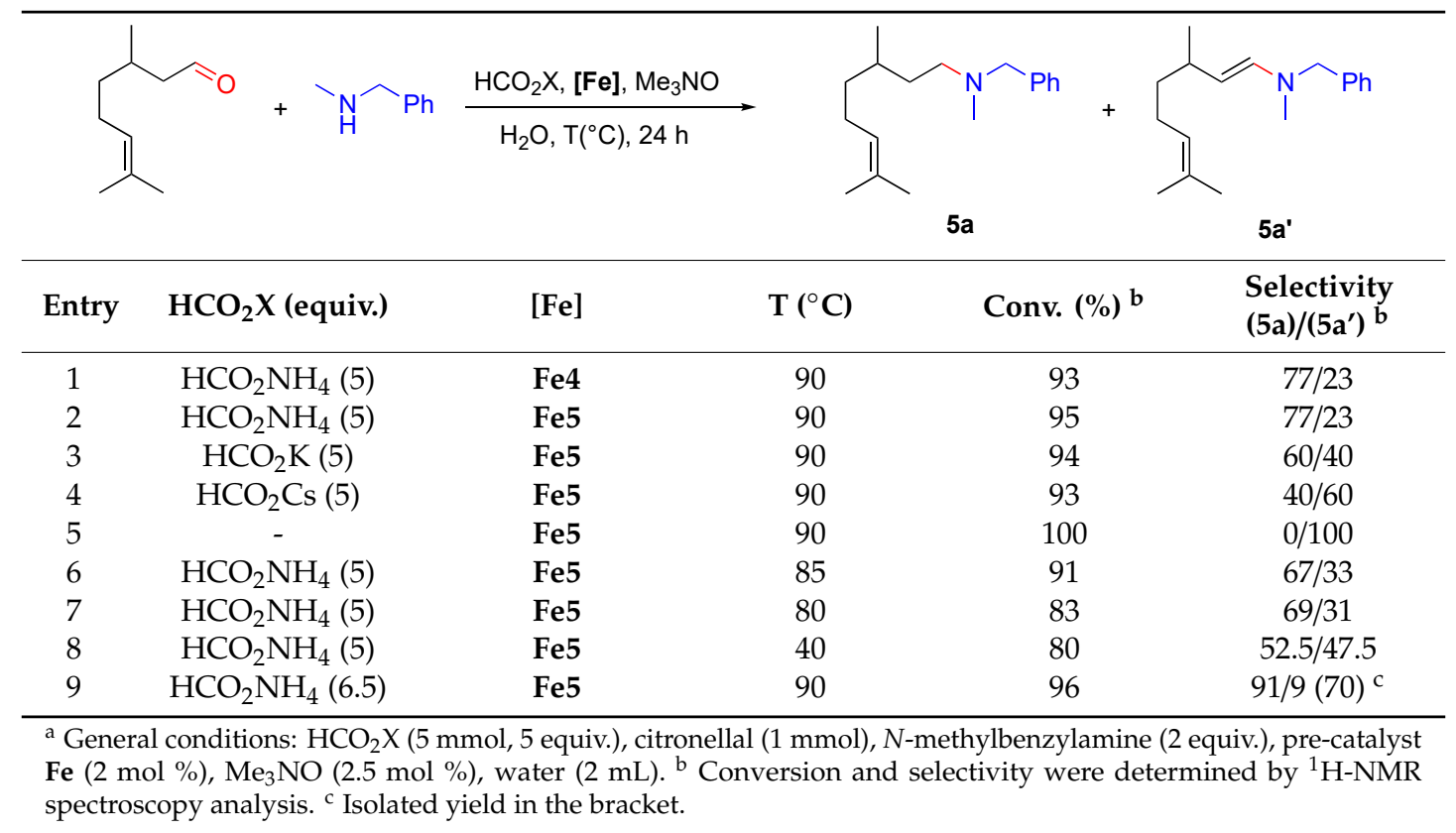

With the optimized conditions in hands, we evaluated some aliphatic and benzylic amines with aromatic and aliphatic aldehydes (Table 4). Whatever the benzylic amine used with citronellal, the isolated yield was good $(\mathbf{5 a}-\mathbf{b}, 61-70 \%)$, while the alkylated amine $\mathbf{5} \mathbf{c}$ was obtained in a low yield $(21 \%)$ from the 2-phenylethylamine (Table 4). Amines $\mathbf{5 d}-\mathbf{k}$ were prepared in $11-64 \%$ yield from various benzaldehydes. First, as observed previously, no reduction of halogen-carbon bonds in the substituted phenyl group was observed, and the corresponding alkylated amines $\mathbf{5 f}-\mathbf{h}$ were obtained in around $50 \%$ yield. The reductive alkylation of $\mathrm{N}$-methylbenzylamine with thiophene carboxaldehyde furnished the corresponding amine in a $64 \%$ yield. The reductive amination with electron-rich benzaldehyde and $\mathrm{N}$-methylbenzylamine led to the alkylated amine $\mathbf{5} \mathbf{j}$ in very modest yields $(13 \%$, Table 4$)$. 
Table 4. Iron-catalyzed reductive amination with ammonium formate ${ }^{\mathrm{a}}$.

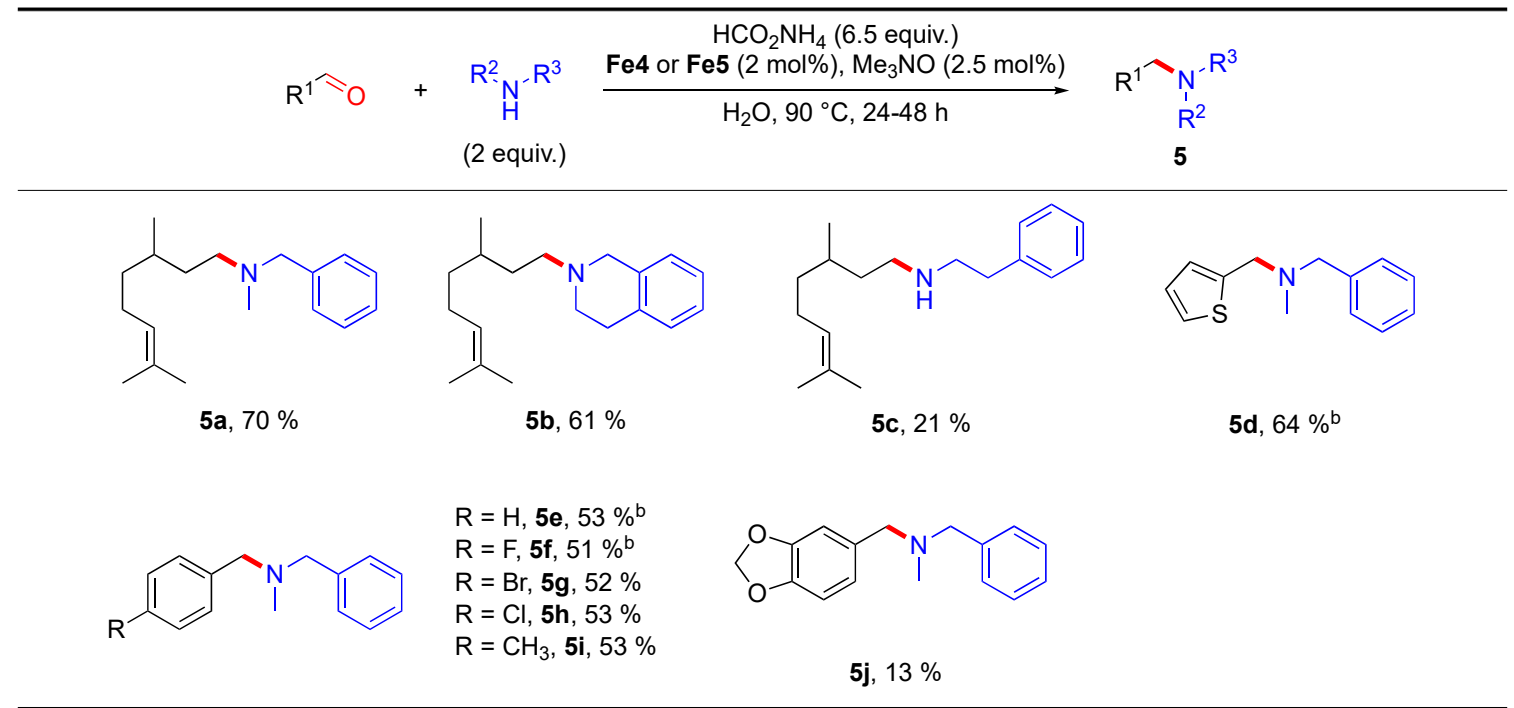

${ }^{\mathrm{a}}$ General conditions: aldehyde (1 mmol), amine (2 equiv.), $\mathrm{HCO}_{2} \mathrm{NH}_{4}(6.5 \mathrm{mmol}, 6.5$ equiv.), pre-catalyst Fe4 or Fe5
$(2 \mathrm{~mol} \%), \mathrm{Me}_{3} \mathrm{NO}(2.5 \mathrm{~mol} \%)$, water $(2 \mathrm{~mL}), 90{ }^{\circ} \mathrm{C}$ for $24 \mathrm{~h} .{ }^{\mathrm{b}}$ for $48 \mathrm{~h}$.

\subsection{Recycling of the Water-Soluble Iron Complex}

One of the main goals, when reactions are carried out in the water, is the study of the recyclability of the complex used. Due to the high solubility of the iron complexes, Fe4-5 in water, separation and recycling should be possible to perform. Fe5-catalyzed, the reductive alkylation of $\mathrm{N}$-methylbenzylamine with citronellal, was chosen as a model reaction for this study. At the end of the first run, ethyl acetate was added under an argon atmosphere to extract the organic compounds, and the aqueous phase was re-engaged directly in another run after the addition of ammonium formate, amine, and aldehyde (Table 5). As showed in Table 5, catalytic activity was maintained after five runs without any decrease in the conversion.

Table 5. Recycling of the pre-catalyst Fe $5^{\mathrm{a}, \mathrm{b}}$.

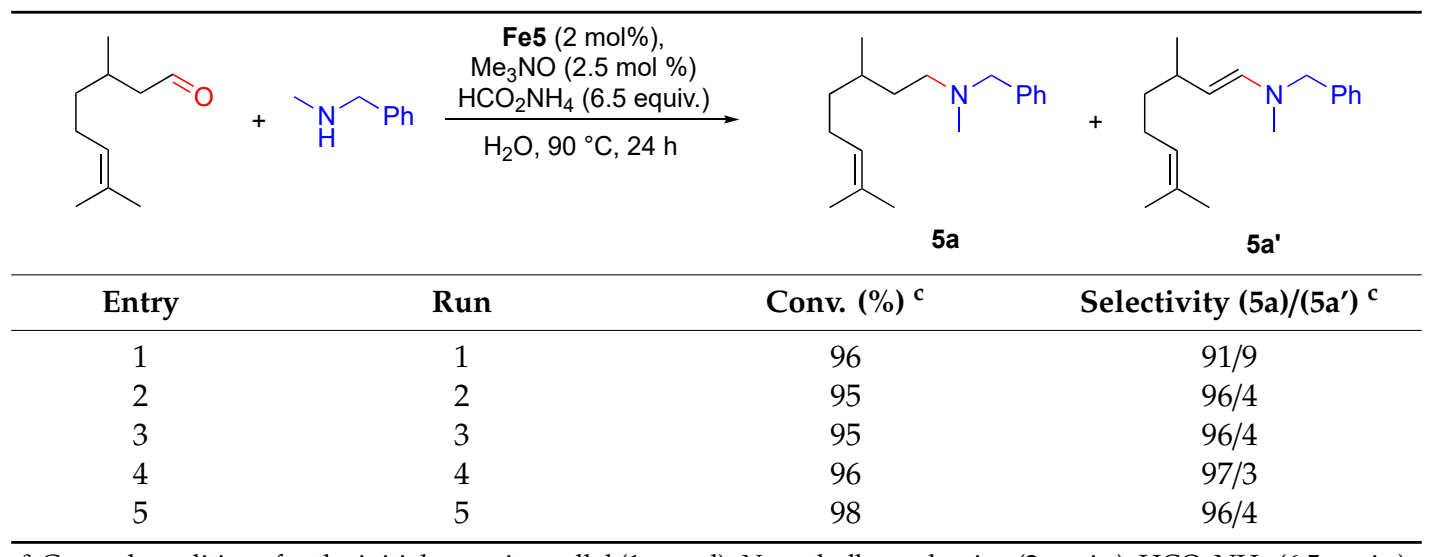

${ }^{a}$ General conditions for the initial run: citronellal (1 mmol), $N$-methylbenzylamine (2 equiv.), $\mathrm{HCO}_{2} \mathrm{NH}_{4}(6.5$ equiv.), pre-catalyst $\mathrm{Fe} 5(2 \mathrm{~mol} \%), \mathrm{Me}_{3} \mathrm{NO}(2.5 \mathrm{~mol} \%)$, water $(2 \mathrm{~mL}), 90^{\circ} \mathrm{C}$ for $24 \mathrm{~h} .{ }^{\mathrm{b}}$ General conditions for run $2-5$ : citronellal (1 mmol), $\mathrm{N}$-methylbenzylamine (2 equiv.), $\mathrm{HCO}_{2} \mathrm{NH}_{4}$ (6.5 equiv.) were added to the former solution, and the mixture was heated to $90{ }^{\circ} \mathrm{C}$. ${ }^{\mathrm{C}}$ Conversion and selectivity were determined by ${ }^{1} \mathrm{H}-\mathrm{NMR}$ spectroscopy analysis.

\section{Materials and Methods}

All air- and moisture-sensitive manipulations were carried out using standard vacuum line Schlenk tubes techniques. All solvent and substrates were degassed prior to use by bubbling argon gas directly in the reaction medium. Other solvents and chemicals were purchased from different 
suppliers and used as received. Deuterated solvents for NMR spectroscopy were purchased from Sigma Aldrich (Saint-Quentin Fallavier, France) and used as received. NMR spectra were recorded on a $500 \mathrm{MHz}$ Bruker spectrometer. Proton $\left({ }^{1} \mathrm{H}\right)$ NMR information is given in the following format: multiplicity (s, singlet; d, doublet; t, triplet; q, quartet; $\mathrm{m}$, multiplet), coupling constant(s) $(J)$ in Hertz $(\mathrm{Hz})$, number of protons, type. The prefix app is occasionally applied when the true signal multiplicity was unresolved, and $b r$ indicates the signal in question broadened. Carbon $\left({ }^{13} \mathrm{C}\right) \mathrm{NMR}$ spectra are reported in ppm $(\delta)$ relative to $\mathrm{CDCl}_{3}$ unless noted otherwise. Infrared spectra were recorded over a PerkinElmer Spectrum 100 FT-IR Spectrometer using neat conditions. HRMS analyses were performed by using the Laboratoire de Chimie Moléculaire et Thioorganique analytical Facilities.

\subsection{General Procedure for the Reduction of Aldehydes}

In a dried flamed Schlenk tube under argon, the corresponding aldehyde (1 equiv.) and sodium formate (5 equiv.) were mixed in water ( $0.5 \mathrm{M}$ solution). The iron complex Fe4 ( $2 \mathrm{~mol} \%)$ and $\mathrm{Me}_{3} \mathrm{NO}$ $(2.5 \mathrm{~mol} \%)$ were then added. The mixture was stirred and heated at $80{ }^{\circ} \mathrm{C}$ for $24 \mathrm{~h}$. After cooling down to room temperature, the resulting solution was quenched with a saturated aqueous solution of sodium bicarbonate and extracted three times with ethyl acetate. The organic phase was dried over $\mathrm{MgSO}_{4}$, filtrated, and concentrated under vacuum to afford the crude product. Purification by flash chromatography on silica gel furnished the alcohol.

\subsection{General Procedure for the Reductive Amination of Aldehydes}

In a dried flamed Schlenk tube under argon, the aldehyde (1 equiv.), the amine (2 equiv.) and ammonium formate (6.5 equiv.) were mixed in water ( $0.5 \mathrm{M}$ solution). The iron complex Fe5 (2 mol \%) and $\mathrm{Me}_{3} \mathrm{NO}$ (2.5 mol \%) were then added. The mixture was stirred and heated at $90{ }^{\circ} \mathrm{C}$ for $24-48 \mathrm{~h}$. After cooling down to room temperature, the resulting solution was quenched with a saturated aqueous solution of sodium bicarbonate and extracted three times with ethyl acetate. The organic phase was dried over $\mathrm{MgSO}_{4}$, filtrated, and concentrated under vacuum to afford the crude product. Purification by flash chromatography on silica gel furnished the amine.

\section{Conclusions}

In conclusion, we have described the application of water-soluble cyclopentadienone iron tricarbonyl complexes in the reduction of aldehydes and in reductive amination under hydride transfer conditions in pure water. Recyclability of iron complex Fe5 was also demonstrated in a model reductive amination. This system tolerated a variety of functional groups such as halides, ethers, heteroaromatic derivatives without impeding the chemical yields. These water-soluble iron complexes allow an efficient, green, and practical procedure for the synthesis of amines and alcohols.

Supplementary Materials: The following are available online. Table S1: Optimization of the reaction conditions for aldehyde reduction by hydride transfer. Table S2: Optimization of the reaction conditions for reductive amination by hydride transfer. Figure S1-S64: The ${ }^{1} \mathrm{H},{ }^{13} \mathrm{C}$, and ${ }^{19} \mathrm{~F}-\mathrm{NMR}$ spectra of compounds.

Author Contributions: Conceptualization-J.-L.R. and S.C.; methodology-J.-L.R.; validation-J.-L.R., S.G. and M.D.M.; formal analysis-S.C. and D.N.; investigation-S.C. and D.N.; resources-J.-L.R.; data curation-S.C. and D.N.; writing-original draft preparation-J.-L.R.; writing-review and editing-J.-L.R., S.G. and M.D.M.; visualization-J.-L.R., S.G. and M.D.M.; supervision-J.-L.R.; project administratio-J.-L.R.; funding acquisition-J.-L.R. and M.D.M. All authors have read and agreed to the published version of the manuscript.

Funding: This research received no external funding.

Acknowledgments: We gratefully acknowledge financial support from the "Ministère de la Recherche et des Nouvelles Technologies", Normandie Université, CNRS, "Région Normandie", and the LABEX SynOrg (ANR-11-LABX-0029). Ademe Agency is acknowledged for a grant to S. C. and Coopération Française-Sénégal for a grant to D. N.

Conflicts of Interest: The authors declare no conflict of interest. 


\section{References}

1. Klingler, F.D. Asymmetric Hydrogenation of Prochiral Amino Ketones to Amino Alcohols for Pharmaceutical Use. Accounts Chem. Res. 2007, 40, 1367-1376. [CrossRef]

2. Hems, W.P.; Groarke, M.; Zanotti-Gerosa, A.; Grasa, G.A. [(Bisphosphine) Ru(II) Diamine] Complexes in Asymmetric Hydrogenation: Expanding the Scope of the Diamine Ligand. Accounts Chem. Res. 2007, 40, 1340-1347. [CrossRef] [PubMed]

3. Johnson, N.B.; Lennon, I.C.; Moran, P.H.; Ramsden, J.A. Industrial-Scale Synthesis and Applications of Asymmetric Hydrogenation Catalysts. Accounts Chem. Res. 2007, 40, 1291-1299. [CrossRef] [PubMed]

4. Saudan, L.A. Hydrogenation Processes in the Synthesis of Perfumery Ingredients. Accounts Chem. Res. 2007, 40, 1309-1319. [CrossRef] [PubMed]

5. Shimizu, H.; Nagasaki, I.; Matsumura, K.; Sayo, N.; Saito, T. Developments in Asymmetric Hydrogenation from an Industrial Perspective. Accounts Chem. Res. 2007, 40, 1385-1393. [CrossRef] [PubMed]

6. Blaser, H.-U.; Studer, M. Cinchona-Modified Platinum Catalysts: From Ligand Acceleration to Technical Processes. Accounts Chem. Res. 2007, 40, 1348-1356. [CrossRef]

7. Blaser, H.-U.; Pugin, B.; Spindler, F.; Thommen, M. From a Chiral Switch to a Ligand Portfolio for Asymmetric Catalysis. Accounts Chem. Res. 2007, 40, 1240-1250. [CrossRef]

8. Shultz, C.S.; Krska, S.W. Unlocking the Potential of Asymmetric Hydrogenation at Merck. Accounts Chem. Res. 2007, 40, 1320-1326. [CrossRef]

9. Wang, N.; Astruc, D. The Golden Age of Transfer Hydrogenation. Chem. Rev. 2015, 115, 6621-6686. [CrossRef]

10. Wang, C.; Wu, X.; Xiao, J. Broader, Greener, and More Efficient: Recent Advances in Asymmetric Transfer Hydrogenation. Chem. Asian J. 2008, 3, 1750-1770. [CrossRef]

11. Wei, D.; Darcel, C. Iron Catalysis in Reduction and Hydrometalation Reactions. Chem. Rev. 2018, 119, 2550-2610. [CrossRef] [PubMed]

12. Liu, W.; Sahoo, B.; Junge, K.; Beller, M. Cobalt Complexes as an Emerging Class of Catalysts for Homogeneous Hydrogenations. Accounts Chem. Res. 2018, 51, 1858-1869. [CrossRef] [PubMed]

13. Ai, W.; Zhong, R.; Liu, X.; Liu, Q. Hydride Transfer Reactions Catalyzed by Cobalt Complexes. Chem. Rev. 2018, 119, 2876-2953. [CrossRef] [PubMed]

14. Filonenko, G.A.; Van Putten, R.; Hensen, E.J.M.; Pidko, E.A. Catalytic (de)hydrogenation promoted by non-precious metals-Co, Fe and Mn: Recent advances in an emerging field. Chem. Soc. Rev. 2018, 47, 1459-1483. [CrossRef] [PubMed]

15. Lindström, U.M. Stereoselective Organic Reactions in Water. Chem. Rev. 2002, 102, 2751-2772. [CrossRef]

16. Cornils, B.; Hermann, W.A. Aqueous-Phase Organometallic Catalysis; Wiley-VCH: Weinheim, Germany, 2002.

17. Robertson, A.; Matsumoto, T.; Ogo, S. The development of aqueous transfer hydrogenation catalysts. Dalton Trans. 2011, 40, 10304-10310. [CrossRef]

18. Wu, X.; Xiao, J. Aqueous Phase Asymmetric transfer hydrogenation of ketones-a greener approach to chiral alcohols. Chem. Commun. 2007, 24, 2449-2466. [CrossRef]

19. Mérel, D.S.; Elie, M.; Lohier, J.-F.; Gaillard, S.; Renaud, J.-L. Bifunctional Iron Complexes: Efficient Catalysts for $\mathrm{C}=\mathrm{O}$ and $\mathrm{C}=\mathrm{N}$ Reduction in Water. ChemCatChem 2013, 5, 2939-2945. [CrossRef]

20. Bohr, M.D.; Bhanushali, M.J.; Nandurkar, N.S.; Bhanage, B.M. Direct Reductive Amination of Carbonyl Compounds with Primary/Secondary Amines Using Recyclable Water-Soluble FeII/EDTA Complex as Catalyst. Tetrahedron Lett. 2008, 49, 965-969. [CrossRef]

21. Thai, T.-T.; Mérel, D.S.; Poater, A.; Gaillard, S.; Renaud, J.-L. Highly active phosphine-free bifunctional iron complex for hydrogenation of bicarbonate and reductive amination. Chem. Eur. J. 2015, 21, 7066-7070. [CrossRef]

22. Lator, A.; Gaillard, S.; Poater, A.; Renaud, J.-L. Iron-Catalyzed Chemoselective Reduction of $\alpha, \beta$-Unsaturated Ketones. Chem. Eur. J. 2018, 24, 5770-5774. [CrossRef] [PubMed]

23. Coufourier, S.; Gaillard, S.; Clet, G.; Serre, C.; Daturi, M.; Renaud, J.-L. A MOF-assisted phosphine free bifunctional iron complex for the hydrogenation of carbon dioxide, sodium bicarbonate and carbonate to formate. Chem. Commun. 2019, 55, 4977-4980. [CrossRef] [PubMed]

24. Seck, C.; Mbaye, M.D.; Coufourier, S.; Lator, A.; Lohier, J.-F.; Poater, A.; Ward, T.R.; Gaillard, S.; Renaud, J. Alkylation of Ketones Catalyzed by Bifunctional Iron Complexes: From Mechanistic Understanding to Application. ChemCatChem 2017, 9, 4410-4416. [CrossRef] 
25. Polidano, K.; Allen, B.D.W.; Williams, J.M.J.; Morrill, L.C. Iron-Catalyzed Methylation Using the Borrowing Hydrogen Approach. ACS Catal. 2018, 8, 6440-6445. [CrossRef]

26. Bettoni, L.; Seck, C.; Mbaye, M.D.; Gaillard, S.; Renaud, J.-L. Iron-Catalyzed Tandem Three-Component Alkylation: Access to $\alpha$-Methylated Substituted Ketones. Org. Lett. 2019, 21, 3057-3061. [CrossRef]

27. Latham, D.E.; Polidano, K.; Williams, J.M.J.; Morrill, L.C. One-Pot Conversion of Allylic Alcohols to $\alpha$-Methyl Ketones via Iron-Catalyzed Isomerization-Methylation. Org. Lett. 2019, 21, 7914-7918. [CrossRef]

28. Lator, A.; Gaillard, S.; Poater, A.; Renaud, J.-L. Well-Defined Phosphine-Free Iron-Catalyzed N-Ethylation and N-Methylation of Amines with Ethanol and Methanol. Org. Lett. 2018, 20, 5985-5990. [CrossRef]

29. Dambatta, M.B.; Polidano, K.; Northey, A.D.; Williams, J.M.J.; Morrill, L.C. Iron-Catalyzed Borrowing Hydrogen C-Alkylation of Oxindoles with Alcohols. ChemSusChem 2019, 12, 2345-2349. [CrossRef]

30. Seck, C.; Mbaye, M.D.; Gaillard, S.; Renaud, J.-L.; Seck-Diouf, C. Bifunctional Iron Complexes Catalyzed Alkylation of Indoles. Adv. Synth. Catal. 2018, 360, 4640-4645. [CrossRef]

31. Bettoni, L.; Gaillard, S.; Renaud, J.-L. Iron-Catalyzed ß-Alkylation of Alcohols. Org. Lett. 2019, 21, 8404-8408. [CrossRef]

32. Polidano, K.; Williams, J.M.J.; Morrill, L.C. Iron-Catalyzed Borrowing Hydrogen $\beta$-C(sp3)-Methylation of Alcohols. ACS Catal. 2019, 9, 8575-8580. [CrossRef]

33. Coufourier, S.; Gaillard, Q.G.; Lohier, J.-F.; Poater, A.; Gaillard, S.; Renaud, J.-L. Hydrogenation of CO2, Hydrogenocarbonate and Carbonate to Formate in Water using Phosphine Free Bifunctional Iron Complexes. ACS Catal. 2020. [CrossRef]

34. Pagnoux-Ozherelyeva, A.; Pannetier, N.; Mbaye, D.M.; Gaillard, S.; Renaud, J.-L. Knölker's Iron Complex: An Efficient In Situ Generated Catalyst for Reductive Amination of Alkyl Aldehydes and Amines. Angew. Chem. Int. Ed. 2012, 51, 4976-4980. [CrossRef] [PubMed]

35. Moulin, S.; Dentel, H.; Gaillard, S.; Poater, A.; Cavallo, L.; Lohier, J.-F.; Renaud, J.-L.; Pagnoux-Ozherelyeva, A. Bifunctional (Cyclopentadienone)Iron-Tricarbonyl Complexes: Synthesis, Computational Studies and Application in Reductive Amination. Chem. A Eur. J. 2013, 19, 17881-17890. [CrossRef] [PubMed]

36. Luh, T.-Y. Trimethylamine N-oxide-A versatile reagent for organometallic chemistry. Coord. Chem. Rev. 1984, 60, 255-276. [CrossRef]

37. Moyer, S.A.; Funk, T.W. Air-Stable iron catalyse for the oppenauer type oxidation of alcohols. Tetrahedron Lett. 2010, 51, 5430-5433. [CrossRef]

38. Johnson, T.C.; Clarkson, G.J.; Wills, M. (Cyclopentadienone)iron Shvo Complexes: Synthesis and applications to hydrogen transfer reactions. Organometallics 2011, 30, 1859-1868. [CrossRef]

39. Plank, T.N.; Drake, J.L.; Kim, D.K.; Funk, T.W. Air-Stable, Nitrile-Ligated (Cyclopentadienone)iron Dicarbonyl Compounds as Transfer Reduction and Oxidation Catalysts. Adv. Synth. Catal. 2012, 354,597-601. [CrossRef]

40. Knölker, H.-J.; Heber, J. Transition Metal-Diene Complexes in Organic Synthesis, Part 18.1 Iron-Mediated [2+ $2+1$ ] Cycloadditions of Diynes and Carbon Monoxide: Selective Demetalation Reactions. Synlett 1993, 12, 924-926. [CrossRef]

41. Knölker, H.-J.; Baum, E.; Heber, J. Transition Metal-Diene Complexes in Organic Synthesis, Part 25.1 Cycloadditions of Annulated 2,5-Bis(trimethylsilyl)cyclopentadienones. Tetrahedron Lett. 1995, 36, 7647-7650. [CrossRef]

42. Knölker, H. Trimethylamine N-Oxide-A useful oxidizing reagent. J. Für Prakt. Chem. 1996, 338, $190-192$. [CrossRef]

43. Knölker, H.-J.; Goesmann, H.; Klauss, R. A Novel Method for the Demetalation of Tricarbonyliron-Diene Complexes by a Photolytically Induced Ligand Exchange Reaction with Acetonitrile. Angew. Chem. Int. Ed. 1999, 38, 702-705. [CrossRef]

44. Knölker, H.-J.; Baum, E.; Goesmann, H.; Klauss, R. Demetalation of Tricarbonyl(cyclopentadienone)iron Complexes Initiated by a Ligand Exchange Reaction with $\mathrm{NaOH}-X$-Ray Analysis of a Complex with Nearly Square-Planar Coordinated Sodium. Angew. Chem. Int. Ed. 1999, 38, 2064-2066. [CrossRef]

45. Abdel-Magid, A.F.; Mehrman, S.J. A Review on the Use of Sodium Triacetoxyborohydride in the Reductive Amination of Ketones and Aldehydes. Org. Process. Res. Dev. 2006, 10, 971-1031. [CrossRef]

46. Nugent, T.C.; El-Shazly, M. Chiral amine synthesis-Recent developments and trends for enamide reduction, reductive amination, and imine reduction. Adv. Synth. Catal. 2010, 352, 753-819. [CrossRef]

47. Alinezhad, H.; Yavari, H.; Salehian, F. Recent Advances in Reductive Amination Catalysis and Its Applications. Curr. Org. Chem. 2015, 19, 1021-1049. [CrossRef] 
48. Gusak, K.N.; Ignatovich, Z.V.; Koroleva, E.V. New potential of the reductive alkylation of amines. Russ. Chem. Rev. 2015, 84, 288-309. [CrossRef]

49. Fleischer, S.; Zhou, S.; Junge, K.; Beller, M. An Easy and General Iron-catalyzed Reductive Amination of Aldehydes and Ketones with Anilines. Chem. Asian J. 2011, 6, 2240-2245. [CrossRef]

50. Lator, A.; Gaillard, Q.G.; Mérel, D.S.; Lohier, J.-F.; Gaillard, S.; Poater, A.; Renaud, J.-L. Room-Temperature Chemoselective Reductive Alkylation of Amines Catalyzed by a Well-Defined Iron(II) Complex Using Hydrogen. J. Org. Chem. 2019, 84, 6813-6829. [CrossRef]

Sample Availability: Samples of the compounds are available from the authors.

(C) 2020 by the authors. Licensee MDPI, Basel, Switzerland. This article is an open access article distributed under the terms and conditions of the Creative Commons Attribution (CC BY) license (http://creativecommons.org/licenses/by/4.0/). 